\title{
Vapor-liquid equilibrium and distillation of mixtures containing formaldehdye and poly(oxymethylene) dimethyl ethers
}

\author{
Niklas Schmitz ${ }^{\mathrm{a}, \mathrm{c}}$, Christian F. Breitkreuz ${ }^{\mathrm{a}, \mathrm{c}}$, Eckhard Ströfer ${ }^{\mathrm{a}, \mathrm{c}}$, \\ Jakob Burger ${ }^{\mathrm{b}, \mathrm{c}, *}$, Hans Hasse ${ }^{\mathrm{a}, \mathrm{c}}$ \\ ${ }^{a}$ University of Kaiserslautern, Laboratory of Engineering Thermodynamics (LTD), \\ Erwin-Schrödinger-Strasse 44, 67663 Kaiserslautern, Germany \\ ${ }^{b}$ Technical University of Munich, Chair of Chemical Process Engineering, Schulgasse 22, \\ 94315 Straubing, Germany \\ ${ }^{c}$ OME Technologies GmbH, Kaiserslautern, Germany
}

\section{Abstract}

Poly(oxymethylene) dimethyl ethers $\left(\mathrm{OME}, \mathrm{H}_{3} \mathrm{C}-\mathrm{O}-\left(\mathrm{CH}_{2} \mathrm{O}\right)_{n}-\mathrm{CH}_{3}\right)$ are promising synthetic diesel fuels. For designing OME production processes, a model for describing the vapor-liquid equilibrium (VLE) in mixtures of (formaldehyde + water + methanol + methylal + OME + trioxane $)$ is needed. Building on previous work of our group, a phyisco-chemical model for the VLE in these mixtures is developed in the present work. For the development and the testing of the model, experiments of different types were carried out: VLE measurements in a thin film evaporator, batch evaporation experiments in an open still, and continuous distillation experiments in a laboratory column. The model predicts the results of the distillation experiments well. It is shown that OME with $n \geq 3$ can be separated as bottom product from mixtures of formaldehyde, water, methanol, methylal,

\footnotetext{
*Corresponding author:

Email address: burger@tum.de (Jakob Burger)
} 
and OME with $n \geq 2$. This separation is a critical step in a novel OME production process that increases the sustainability of OME production.

\section{Highlights:}

- A model for describing the vapor-liquid equilibrium (VLE) in mixtures of (formaldehyde + water + methanol + methylal + OME + trioxane $)$ is presented.

- The VLE model is successfully used for describing batch evaporation and continuous distillation experiments.

- OME with $n \geq 3$ are separated from a complex reactive multicomponent mixture by distillation.

Keywords: Poly(oxymethylene) dimethyl ethers (OME), Formaldehyde, Vapor-liquid equilibrium, Distillation

\section{Introduction}

Poly(oxymethylene) dimethyl ethers (OME) are oxygenates of the structure $\mathrm{H}_{3} \mathrm{C}-\mathrm{O}-\left(\mathrm{CH}_{2} \mathrm{O}\right)_{n}-\mathrm{CH}_{3}$ with $n \geq 2$. OME of chain lengths $n=3-5$ are environmentally-benign diesel fuels, which reduce the soot and indirectly also the $\mathrm{NO} x$ formation in engines [1-4]. OME can also be used as fuels in

fuel cells [5, 6], as green solvents for producing hydrogen peroxide [7], and as physical solvents for the absorption of $\mathrm{CO}_{2}$ from natural gas $[8,9]$.

Recent studies suggest to produce OME $(n=3-5)$ directly from formaldehyde and methanol in an aqueous environment [10-15]. This route avoids the production of further intermediates, such as trioxane and methylal. In these processes, the reactor outlet is a complex multicomponent mixture 
containing the overall components formaldehyde, water, methanol, methylal, and OME of various chain lengths. Small amounts of trioxane are found as by-product [14]. In these mixtures, formaldehyde $\left(\mathrm{FA}, \mathrm{CH}_{2} \mathrm{O}\right)$ reacts with water $\left(\mathrm{H}_{2} \mathrm{O}\right)$ to poly (oxymethylene) glycols $\left(\mathrm{MG}_{n}, \mathrm{HO}-\left(\mathrm{CH}_{2} \mathrm{O}\right)_{n}-\mathrm{H}\right)$ and with methanol (MeOH, $\left.\mathrm{H}_{3} \mathrm{C}-\mathrm{OH}\right)$ to poly(oxymethylene) hemiformals $\left(\mathrm{HF}_{n}\right.$, $\left.\mathrm{HO}-\left(\mathrm{CH}_{2} \mathrm{O}\right)_{n}-\mathrm{CH}_{3}\right)[16,17]$, c.f. reactions (1) to (4).

$$
\begin{aligned}
\mathrm{FA}+\mathrm{H}_{2} \mathrm{O} & \rightleftharpoons \mathrm{MG}_{1} \\
\mathrm{FA}+\mathrm{MG}_{n-1} & \rightleftharpoons \mathrm{MG}_{n} ; n \geq 2 \\
\mathrm{FA}+\mathrm{MeOH} & \rightleftharpoons \mathrm{HF}_{1} \\
\mathrm{FA}+\mathrm{HF}_{n-1} & \rightleftharpoons \mathrm{HF}_{n} ; n \geq 2
\end{aligned}
$$

The chemical equilibrium of reactions (1) and (3) in the liquid phase is far on the side of the products, i.e. the amount of monomeric formaldehyde in these solutions is very small. For the design of OME production processes, a model for describing the vapor-liquid-equilibrium (VLE) in these mixtures is needed. Such a model is developed here. Wherever no acidic catalysts are present, e.g. in the distillation columns, methylal, OME and trioxane are considered to be chemically inert $[14,18,19]$. However, reactions (1) to (4) are taken into account explicitly following the pioneering work of Maurer [20].

Whereas, experimental data on the liquid-liquid equilibrium (LLE) in various OME-containing systems are available [14], only few experimental data are available on the VLE in systems containing OME. Schappals et al. [9] measured the gas solubility of $\mathrm{CO}_{2}$ in $\mathrm{OME}_{2}, \mathrm{OME}_{3}$, and $\mathrm{OME}_{4}$, respectively. Song et al. [21] measured the VLE in the systems (methylal $\left.+\mathrm{OME}_{2}\right)$ and $\left(\right.$ methanol $\left.+\mathrm{OME}_{2}\right)$ at atmospheric pressure. Burger et 
al. [22] measured the VLE in the system $\left(\mathrm{OME}_{2}+\right.$ trioxane) at 696 mbar and 889 mbar. This work extends the experimental data by VLE measurements in the systems (formaldehyde + water $+\mathrm{OME}_{2}$ ) and (formaldehyde + water + methanol $\left.+\mathrm{OME}_{2}\right)$ at 950 mbar. The latter system is studied at low water concentrations.

Furthermore, batch evaporation and continuous distillation experiments were carried out in the present work. Two batch evaporation experiments with mixtures of (formaldehyde + water + me-thanol + OME + trioxane) were carried out in an open still. The continuous distillation experiments were carried out in a DN50 distillation column in mixtures of (water + methanol + methylal $+\mathrm{OME}_{2}+$ trioxane) and (formaldehyde + water + methanol $+\mathrm{OME}_{2}+\mathrm{OME}_{3}+$ trioxane). For each system, two continuous distillation experiments were carried out at varying reflux ratios. The batch evaporation and distillation experiments were carried out at atmospheric pressure.

Recently, a new process for producing OME has been described, in which OME with $n \geq 3$ are separated from mixtures of formaldehyde, water, methanol, methylal, and OME with $n \geq 2$ by distillation [23]. The two batch evaporation experiments and the continuous distillation experiments in the system that were carried in the present work, prove the feasibility of this separation.

Starting with the work of Maurer [20], a physico-chemical model for describing the VLE and the LLE in formaldehyde-containing mixtures has been developed and tested in our group [16-20, 24-32]. In the model, the nonideality in the liquid phase is described using a UNIFAC-based activity co- 
efficient model. The chemical reactions (1) to (4) are explicitly considered. Ott et al. [33] showed that this is necessary to obtain reliable simulations of distillation of formaldehyde-containing mixtures.

Of particular relevance for the present work is the model of Kuhnert et al. [19] It was tested using experimental data for VLE and LLE in the system (formaldehyde + water + methanol + methylal) [19] and was successfully used for describing distillation in a methylal production process [34]. That model was recently extended to include also OME with $n \geq 2$ [32]. The extension was, however, parametrized and validated using only LLE and not VLE in OME-containing systems. This gap is closed in the present work. Both, the experimental VLE data obtained in the present work and the literature data are used and a new model version is reported. Furthermore, trioxane is added to the model by adopting further interaction parameters from the work of Albert [18], who described the system (formaldehyde + water + methanol + trioxane). As a result, the system (formaldehyde + water + methanol + methylal + OME + trioxane) is described by the model, which is developed in the present work.

It is shown that the new physico-chemical model gives a good description of the VLE experiments, as well as that it can be used for describing the batch evaporation and continuous distillation experiments. For the batch evaporation experiments, the experimental composition and the temperature of the liquid residue are compared to calculations of the residue curve using Rayleigh's equation [35], where it is assumed that the emerging vapor is in equilibrium with the liquid residue. For the continuous distillation experiments, the experimental concentration and temperature profiles are 
compared to simulations combining the new physico-chemical model with the equilibrium-stage model of a distillation column.

\section{Experiments}

\subsection{Chemicals}

Paraformaldehyde $(\geq 0.95 \mathrm{~g} / \mathrm{g}$ ) was obtained from Carl Roth. Ultrapure Milli-Q water was produced with a purification system from Merck. Aqueous and methanolic formaldehyde solutions were prepared by dissolving paraformaldehyde in water and methanol, respectively, at elevated temperatures. The procedure is described elsewhere [14]. Methanolic formaldehyde solutions were dried over Zeolite 3A obtained from Carl Roth. As the solutions could not be dried completely, instead of studying the VLE in the system (formaldehyde + methanol $+\mathrm{OME}_{2}$ ), the system (formaldehyde + water + methanol $+\mathrm{OME}_{2}$ ) was studied at low water concentrations. $\mathrm{OME}_{2}$

$(\geq 0.985 \mathrm{~g} / \mathrm{g})$ and $\mathrm{OME}_{3}(0.83 \mathrm{~g} / \mathrm{g}$, containing $0.17 \mathrm{~g} / \mathrm{g}$ trioxane $)$ were provided by $\mathrm{OME}$ Technologies $\mathrm{GmbH}$. $\mathrm{OME}_{3}$ with trioxane as impurity was only used in the evaporation and distillation experiments. Trioxane was considered in the analysis. For safety reasons, all mixtures were checked to be free of peroxides using a colorimetric peroxide test from Merck before used in the experiments.

\subsection{Vapor-liquid equilibrium}

The VLE was measured in a thin-film evaporator. The experimental set-up and procedure are described in the work of Hasse [36] and Albert et al. [26] and are not repeated here. The temperature was measured with a 
Pt100 resistance thermometer with an accuracy of $\pm 0.1 \mathrm{~K}$. All experiments were carried out at a pressure of $950 \pm 0.5$ mbar. The pressure was measured with a pressure sensor with a relative accuracy of $\pm 0.4 \%$.

\subsection{Batch evaporation}

Batch evaporation experiments were carried out in a three-neck round bottom flask (volume $500 \mathrm{~mL}$ ), which was heated with an electrical heating

jacket. About $300 \mathrm{~mL}$ of liquid were filled in the round bottom flask. The mixture in the flask was heated slowly and evaporated over a period of about 3 hours. The temperature of the liquid residue was measured with a Pt100 resistance thermometer (introduced through a seal in one of the necks) with an accuracy of $\pm 0.1 \mathrm{~K}$. Samples of the liquid residue were withdrawn through a septum that was connected to another neck of the flask. The third neck of the flask was connected to a Liebig condenser, where the emerging vapor was condensed and then collected in a flask. The batch evaporation experiments were carried out at ambient pressure, which was determined with a mercury pressure meter with an accuracy of about \pm 10 mbar.

\subsection{Continuous distillation}

Distillation experiments were carried out in a continuously-operated laboratory glass distillation column with $50 \mathrm{~mm}$ inner diameter from Iludest. Details on the set up of the column are given in the work of Drunsel [37] and Weidert et al. [34] The column consists of six sections, each containing $0.48 \mathrm{~m}$ structured packing Sulzer CY. The temperatures were measured in the reboiler, after each section, and at the top of the column using Pt100 resistance thermometers with an accuracy of $\pm 0.3 \mathrm{~K}$. The pressure was measured at 
the top of the column using a pressure sensor. The accuracy is \pm 0.5 mbar. The pressure drop along the column was measured with a membrane differential pressure sensor. The column is equipped with an electrically heated thermosyphon reboiler. An inert atmosphere was established by through-flow of gaseous nitrogen. The feed was preheated and the feed temperature was controlled. The mass flows of the feed and the reflux were also controlled. They were both measured by coriolis flow meters from Rheonik. The relative accuracy of the flow meters is $\pm 0.5 \%$. The mass flows of the distillate and the bottom product were measured with scales: the change of mass with time was linearly regressed to obtain the mass flows. In preliminary experiments, the relative accuracy of this method was determined to be $\pm 5 \%$ by comparing with mass flows measured with the flow meters. The heat duty of the reboiler, which is the remaining degree of freedom for steady-state operation, was set to a constant value.

For the start-up, the reboiler of the column was filled with the feed mixture and heated and the column was operated at infinite reflux. Then the feed mass flow, the reflux mass flow, and the heat-duty of the reboiler were set. Steady-state was achieved after several hours of operation, typically 7 - 8 hours were needed. This was checked by monitoring the temperature profiles and, in addition, by consecutive sampling at selected sections of the column. After steady-state was achieved, the column was operated for at least one more hour until a set of samples from the liquid phase was drawn from all sections of the column, from the feed, and from the distillate and the bottom product, respectively. 


\subsection{Analysis}

In reactive mixtures of formaldehyde, water, methanol, and inert components, as they are studied here, the composition can be described in two different ways. The true concentrations account for the poly(oxymethylene) glycols and poly(oxymethylene) hemiformals. In the present work, only overall concentrations were measured. Thereby the formation of poly(oxymethylene) glycols and poly(oxymethylene) hemiformals is disregarded, i.e. these species are treated as if they were split into formaldehyde, water, and methanol.

The overall mass fractions of methanol, methylal, all OME, and trioxane were measured by gas chromatography using 1,4-dioxane as internal standard and a flame ionization detector for signal detection. The details of the chromatographic method were published previously [14]. The relative accuracy is $5 \%$ for the overall mass fraction of methanol and $2 \%$ for the overall mass fractions of all other components [14] The overall mass fraction of formaldehyde was measured with the sodium sulfite titration method with a relative accuracy of $2 \%$ [14]. The overall mass fraction of water was measured by Karl Fischer titration with a relative accuracy of $2 \%$ [14]. All vapor phase samples of the VLE measurements in the system (formaldehyde + water $\left.+\mathrm{OME}_{2}\right)$ separated into two liquid phases upon condensation. Methanol was added to those samples prior to the analysis, such that a monophasic system was obtained. Methanol has a very strong solubilizing effect on the miscibility gap of OME and water [32]. 


\section{Physico-chemical model}

A scheme of the VLE in the system (formaldehyde + water + methanol + methylal + OME + trioxane) is shown in Figure 1. The chemical equilibrium of reactions (1) to (4) in the liquid phase is described by activity-based chemical equilibrium constants, as given in Eqs. (5) to (8),

$$
\begin{aligned}
& K_{a, \mathrm{MG}_{1}}(T)=\frac{a_{\mathrm{MG}_{1}}}{a_{\mathrm{FA}} \cdot a_{\mathrm{H}_{2} \mathrm{O}}} \\
& K_{a, \mathrm{MG}_{n}}(T)=\frac{a_{\mathrm{MG}_{n}}}{a_{\mathrm{FA}} \cdot a_{\mathrm{MG}_{n-1}}} ; n \geq 2 \\
& K_{a, \mathrm{HF}_{1}}(T)=\frac{a_{\mathrm{HF}_{1}}}{a_{\mathrm{FA}} \cdot a_{\mathrm{MeOH}}} \\
& K_{a, \mathrm{HF}_{n}}(T)=\frac{a_{\mathrm{HF}_{n}}}{a_{\mathrm{FA}} \cdot a_{\mathrm{HF}_{n-1}}} ; n \geq 2
\end{aligned}
$$

where $a_{i}=x_{i} \cdot \gamma_{i}$ are the activities and $\gamma_{i}$ are the activity coefficients of component $i$. Temperature-dependent correlations for describing the chemical equilibrium constants were taken from Drunsel et al. [38] and are given in Table 1. For all calculations, the maximal chain length of poly(oxymethylene) glycols and poly(oxymethylene) hemiformals in the liquid phase is limited to $n=10$. The VLE is calculated from the extended Raoult's law. The vapor phase is assumed to be a mixture of ideal gases. Poly(oxymethylene) glycols and poly(oxymethylene) hemiformals with $n \geq 2$ are not considered in the vapor phase. The chemical equilibrium of reactions (1) and (3) in the vapor phase is modeled indirectly by combining the chemical equilibrium in the liquid phase and the phase equilibrium. Vapor-pressure correlations for all components were adopted from the literature and are given in the Supplementary Information. The non-ideality of the liquid phase is described using a UNIFAC-based activity coefficient model of the system. The struc- 
tural groups in the system (formaldehyde + water + methanol + methylal + OME + trioxane) are given in Table 2, which also contains the size and surface parameters $R$ and $Q$ of the groups. The UNIFAC group assignment is given in Table 3. Monomeric formaldehyde, water, methanol, methylal, and trioxane are modeled as individual groups. An OME of chain length $n$ consists of one $\mathrm{H}_{3} \mathrm{C}-\mathrm{O}-\mathrm{CH}_{2} \mathrm{O}-\mathrm{CH}_{3}$ group (methylal) and $(n-1)\left(\mathrm{CH}_{2} \mathrm{O}\right)_{\mathrm{OME}}$ groups [32].

The UNIFAC group interaction parameters are given in Table 4. Interaction parameters between groups 1 - 9 were adopted from Kuhnert et al. [19] without modification. They were originally fitted to VLE and LLE data in the system (formaldehyde + water + methanol + methylal). Schmitz et al. [32] suggested to add one more UNIFAC group, namely the group $\left(\mathrm{CH}_{2} \mathrm{O}\right)_{\text {OME }}$ to consider OME, and report interaction parameters of that group with groups $1-9$. However, it turns out that the parametrization, which was established using LLE data, does yield a good description of VLE in the system (formaldehyde + water + methanol + OME). Therefore, the interaction parameters between groups $\left(\mathrm{CH}_{2} \mathrm{O}\right)_{\mathrm{OME}}$ and $\mathrm{CH}_{3} \mathrm{OH}$, as well as those between groups $\left(\mathrm{CH}_{2} \mathrm{O}\right)_{\text {OME }}$ and $\mathrm{CH}_{2} \mathrm{OH}$ were fitted to experimental VLE data in the present work, as described in more detail below. The remaining parameters of group $\left(\mathrm{CH}_{2} \mathrm{O}\right)_{\mathrm{OME}}$ were adopted from Schmitz et al. [32] without any changes.

The interaction parameters between group $\left(\mathrm{CH}_{2} \mathrm{O}\right)_{\mathrm{OME}}$ and group $\mathrm{CH}_{3} \mathrm{OH}$ (parameters $a_{9,10}$ and $a_{10,9}$, c.f. Table 4 ) were fitted in the present work to the binary VLE of the system (methanol $+\mathrm{OME}_{2}$ ) measured by Song et al. [21] In the parameter fit, the temperature and the pressure were set and the devi- 
ation between the experimental and calculated mass fractions of methanol in the vapor and the liquid phase were minimized using a maximum-likelihood method. The uncertainty of the mass fraction of methanol in both phases from the measurements of Song et al. [21] was assumed to be $2 \%$.

The interaction parameters between group $\left(\mathrm{CH}_{2} \mathrm{O}\right)_{\mathrm{OME}}$ and group $\mathrm{CH}_{2} \mathrm{OH}$ (parameters $a_{8,10}$ and $a_{10,8}$, c.f. Table 4) were fitted in the present work to the VLE data in the system (formaldehyde + water + methanol $+\mathrm{OME}_{2}$ ), which were measured in the present work. Group $\mathrm{CH}_{2} \mathrm{OH}$ is part of hemiformal and poly(oxymethylene) hemiformals, c.f. Table 3. In the parameter fit, the overall composition of the liquid phase and the pressure were set and the deviation between the experimental and calculated overall mass fractions of all components in the vapor phase were minimized. Adding the deviation between the experimental and calculated temperature as an additional objective did not improve the fit. Again, a maximum-likelihood method was used for the parameter fit. The uncertainty of the overall mass fractions of all components in the vapor phase was considered as discussed in Section 2.5. All parameter fits were carried out using the software gProms Model Builder V. 3.7.1 (Process Systems Enterprise).

All interaction parameters of group $\left(\mathrm{CH}_{2} \mathrm{O}\right)_{3}$ (trioxane) were adopted from Albert [18], who describes a VLE model of the system (formaldehyde + water + methanol + trioxane). The work of Albert [18] contains no information on parameters for the interactions of group $\left(\mathrm{CH}_{2} \mathrm{O}\right)_{3}$ with groups $\mathrm{H}_{3} \mathrm{C}-\mathrm{O}-\mathrm{CH}_{2} \mathrm{O}-\mathrm{CH}_{3}$ and $\left(\mathrm{CH}_{2} \mathrm{O}\right)_{\mathrm{OME}}$. These two groups are used here to model methyal and OME, c.f. Table 3. To describe the system (formaldehyde + water + methanol + methylal + OME + trioxane $)$ in the 
present work, these parameters are set to zero. This is motivated by measurements of Burger et al. [22], who report that the binary VLE in the system $\left(\mathrm{OME}_{2}+\right.$ trioxane $)$ is almost ideal.

The fit of the UNIFAC interaction parameters in the present work exclusively affects the activity coefficients in OME-containing systems with formaldehyde and/or methanol. In our previous work, we have investigated the LLE in the system (water + methanol + OME) [32] and distillation boundaries in the system (formaldehyde + methanol + OME) [23] using the previous model that was established using only LLE data. It is shown in the Supplementary Information that the new model of the present work still provides a good description of the LLE and that the calculation of the distillation boundaries is not significantly influenced. In addition, in previous work, we have determined activity-based chemical equilibrium constants of the acid-catalyzed OME formation form formaldehyde and methanol in aqueous solutions [14]. When used together with the new activity coefficient model, the numbers for these chemical equilibrium constants should be modified as described in the Supplementary Information.

\section{Results and discussion}

\subsection{Vapor-liquid equilibrium}

Figure 2 shows the VLE in the system (methanol $+\mathrm{OME}_{2}$ ) and Figure 3 shows the VLE in the system (methylal $+\mathrm{OME}_{2}$ ). Both systems are studied at 1.013 bar. The model of the present work describes the experimental VLE data from Song et al. [21] well. For the system (methanol $+\mathrm{OME}_{2}$ ), two interaction parameters were fitted to the experimental VLE data (see 
above), whereas for the system (methylal $+\mathrm{OME}_{2}$ ), the model results are predictions. At the experimental pressure and temperature, the arithmetic mean of the absolute deviations between the mass fraction of $\mathrm{OME}_{2}$ in both phases is $0.008 \mathrm{~g} / \mathrm{g}$ for the system (methanol $+\mathrm{OME}_{2}$ ) and $0.012 \mathrm{~g} / \mathrm{g}$ for the system (methylal $+\mathrm{OME}_{2}$ ).

Numerical results of the VLE measurements carried out in the present work for the system (formaldehyde + water $+\mathrm{OME}_{2}$ ) are given in Table 5 . The corresponding results for the system (formaldehyde + water + methanol $+\mathrm{OME}_{2}$ ) are given in Table 6. The experimental and the calculated tie lines in the system (formaldehyde + water $+\mathrm{OME}_{2}$ ) are shown in Figure 4. The experimental feed points coincide with the experimental tie lines indicating reliable sampling and analysis. As no parameters were fitted to the experimental VLE data in this system, the model results are predictions. It can be seen that there is generally a good agreement between the experimental tie lines and the model results. Except for the tie line with the highest overall mass fractions of $\mathrm{OME}_{2}$, the slope of the calculated tie lines is in good agreement with the experiments. In most cases, $\mathrm{OME}_{2}$ is enriched in the vapor phase. The overall mass fractions of $\mathrm{OME}_{2}$ in the vapor phase are, however, predicted too low. The tie line with the highest overall mass fraction of $\mathrm{OME}_{2}$ shows a qualitatively different behavior. Here, $\mathrm{OME}_{2}$ is depleted in the vapor phase indicating a ternary azeotrope and a distillation boundary. At the experimental composition of the liquid phase and the experimental pressure, the arithmetic mean of the absolute deviations between the overall mass fraction in the vapor phase is $0.016 \mathrm{~g} / \mathrm{g}$ for formaldehyde, $0.046 \mathrm{~g} / \mathrm{g}$ for water, and $0.051 \mathrm{~g} / \mathrm{g}$ for $\mathrm{OME}_{2}$. The measured temperature is 
between $358 \mathrm{~K}$ and $367 \mathrm{~K}$, c.f. Table 5 . The arithmetic mean of the absolute deviations for the temperature is $2.5 \mathrm{~K}$.

Figure 5 shows the experimental and the calculated tie lines in the system (formaldehyde + water + methanol $+\mathrm{OME}_{2}$ ). The system is studied at low water concentrations. The largest overall mass fraction of water is $0.027 \mathrm{~g} / \mathrm{g}$ and found in the vapor phase. For the graphical illustration in Figure 5, the concentrations are projected into the ternary system (formaldehyde + methanol $+\mathrm{OME}_{2}$ ) by proportional weighting. Water was, however, considered in the analysis and the model calculation. Again, the experimental feed points coincide with the experimental tie lines. It can be seen that there is a good agreement between the experimental tie lines and the model results. For the tie line with the lowest overall mass fractions of formaldehyde, the agreement is excellent, whereas for all other tie lines the overall mass fractions of formaldehyde in the vapor phase are calculated too low. The tie line with the lowest overall mass fractions of formaldehyde shows a different direction than the other tie lines. Here, $\mathrm{OME}_{2}$ is depleted in the vapor phase, whereas for all other tie lines, $\mathrm{OME}_{2}$ is enriched in the vapor phase. The arithmetic mean of the absolute deviations between the overall mass fraction in the vapor phase is $0.037 \mathrm{~g} / \mathrm{g}$ for formaldehyde, $0.002 \mathrm{~g} / \mathrm{g}$ for water, $0.007 \mathrm{~g} / \mathrm{g}$ for methanol, and $0.034 \mathrm{~g} / \mathrm{g}$ for $\mathrm{OME}_{2}$. The measured temperature is between $350 \mathrm{~K}$ and $364 \mathrm{~K}$, c.f. Table 6 . The arithmetic mean of the absolute deviations for the temperature is $1.4 \mathrm{~K}$.

\subsection{Batch evaporation}

Two batch evaporation experiments with different feed compositions were carried out in the system (formaldehyde + water + methanol + OME + tri- 
oxane). Numerical results of the two batch evaporation experiments (overall composition and temperature of the liquid residue) are given in the Supplementary Information. The results are illustrated in Figure 6 for experiment B1 and in Figure 7 for experiment B2. For both experiments, the composition in the liquid residue approaches pure $\mathrm{OME}_{3}$ showing that $\mathrm{OME}_{3}$ (and therefore also OME with $n \geq 4$ ) can be separated from the residual components of the system. In Figure 6 and Figure 7, the experimental results are additionally compared to calculations of the residue curve using Rayleigh's equation [35],

$$
\frac{\mathrm{d} \tilde{x}_{i}^{(m)}}{\mathrm{d} \tau}=-\left(\tilde{y}_{i}^{(m)}-\tilde{x}_{i}^{(m)}\right)
$$

where $\tilde{x}_{i}^{(m)}, \tilde{y}_{i}^{(m)}$ are the overall mass fractions of the liquid residue, and the emerging vapor, respectively, and $\tau$ is a dimensionless time parameter. It is assumed that the VLE between the liquid residue and the emerging vapor is always established. For the calculation of the VLE, the chemical reactions were explicitly considered, see the description of the physico-chemical model. The initial composition of the liquid mixture was used as initial condition for the numerical integration of Eq. (9). The temperature $T\left(p, \tilde{x}_{i}^{(m)}\right)$ is obtained from the VLE model. Figure 6 and Figure 7 show that there is generally a good agreement between the experimental data and the calculations for both batch evaporation experiments. However, increasing deviations are observed for increasing overall mass fractions of formaldehyde in the liquid residue, see the results at about $100{ }^{\circ} \mathrm{C}$ in Figure 6 . Here, the highest overall mass fraction of formaldehyde in the liquid residue is observed. At this point of the experiment also solid precipitation of formaldehyde in the Liebig condenser was observed, which is caused by high concentrations of formaldehyde in the 
emerging vapor and low temperatures in the condenser.

\subsection{Continuous distillation}

Four continuous distillation experiments were carried out in the present work at atmospheric pressure: two experiments in the system (water + methanol + methylal $+\mathrm{OME}_{2}+$ trioxane) and two experiments in the system (formaldehyde + water + methanol $+\mathrm{OME}_{2}+\mathrm{OME}_{3}+$ trioxane). The two experiments that were carried out within each system differ in the reflux ratio. For the latter system, also the feed position was varied. Numerical results for the liquid phase composition and the temperature profiles for the distillation experiments are given in the Supplementary Information. The results for distillation experiment D1 in the system (water + methanol + methylal $+\mathrm{OME}_{2}+$ trioxane) are shown in Figure 8. A stream table of the corresponding experiment is given in Table 7 . The experimental data are the original measurement data, no reconciliation was carried out. For experiment $\mathrm{D} 1$, the relative error in the total mass balance is $1.4 \%$. The relative errors in the component mass balances are in the same order. Figure 8 shows that the simulation of the column profiles with the equilibrium-stage model agrees well with the experimental profiles. In the simulation, the HETP value of the used Sulzer CY packing was taken as $0.1 \mathrm{~m}$. This is in agreement with the product data sheet and previous experiments using the same column and the same packing [34]. The enthalpy model that was used is a combination of the models of Albert [18] for the system (formaldehyde + water + methanol) and Burger [4] for the system (methylal $+\mathrm{OME}_{n}+$ trioxane). For a fully specified feed and column pressure, there are two degrees of freedom left for the simulation of the column. Based on preliminary sensitivity studies, the 
mass fraction of $\mathrm{OME}_{2}$ at $0.48 \mathrm{~m}$ and the reflux ratio were specified here.

The overall composition profile in the liquid phase and the temperature profile of continuous distillation experiment D2 in the system (formaldehyde + water + methanol $+\mathrm{OME}_{2}+\mathrm{OME}_{3}+$ trioxane) are shown in Figure 9. A stream table of the corresponding experiment is given in Table 8. For experiment D2, the relative error in the total mass balance is $5.6 \%$. The relative error is in the range of the measurement uncertainty of the flow measurement using scales, see above. The relative errors in the component mass balances are in the same order. Figure 9 shows that the simulation of the column profiles with the equilibrium-stage model agrees well with the experimental profiles. Again, the HETP value of the packing was taken as $0.1 \mathrm{~m}$. In the simulation, the overall mass fraction of $\mathrm{OME}_{3}$ at $0.48 \mathrm{~m}$ and the overall mass fraction of formaldehyde at $1.44 \mathrm{~m}$ were specified.

As formaldehyde is present in experiment D2, the chemical reactions (1) to (4) are considered in the simulation. It is assumed that the chemical equilibrium is established on each stage. Since the simulation and the experiments agree well, there is no need to increase the model complexity and use a model, in which the chemical reactions are kinetically controlled. This is also justified, because the temperatures in the column are comparably high, c.f. the temperature profile in Figure 9, leading to fast kinetics. Table 8 shows that in distillation experiment $\mathrm{D} 2, \mathrm{OME}_{3}$ is quantitatively separated as bottom product from all other components of the system. As mentioned above, this separation occurs in a novel OME production process [23]. The experiment D2 shows that the separation is feasible in a continuously-operated distillation column. The operating point (feed composition, pressure) of the 
column in the OME production process [23] is, however, different from the operating point in experiment D2 in the present work. This gap should be closed in future work.

Information on the two continuous distillation experiments D3 and D4, which do not yield additional qualitative insights, is given in the Supplementary Information. Again, good agreement between the experimental column profiles and simulations using the equilibrium-stage model is observed.

\section{Conclusion}

In the present work, a physico-chemical model for describing the vaporliquid equilibrium (VLE) in the system (formaldehyde + water + methanol + methylal + OME + trioxane) is described. For developing and testing of the model, different experiments were carried out: VLE measurements in the systems (formaldehyde + water $+\mathrm{OME}_{2}$ ) and (formaldehyde + water + methanol $\left.+\mathrm{OME}_{2}\right)$ at 950 mbar, as well as batch evaporation experiments and continuous distillation experiments at atmospheric pressure. Despite the high phyisco-chemical complexity of the studied mixtures, the model is successful in describing all experiments. The continuous distillation experiments show that OME with $n \geq 3$ can be separated as bottom product from mixtures of formaldehyde, water, methanol, methylal, and OME with $n \geq 2$. This is the critical separation in a newly developed OME production process [23]. It is, hence, shown to be feasible. The physico-chemical model can be used for detailed simulations of this separation and other OME production processes. 


\section{Nomenclature}

$\begin{array}{ll}\text { Abbreviations } \\ \text { FA } & =\text { Formaldehyde } \\ \text { HETP } & =\text { Height equivalent to a theoretical plate } \\ \text { HF } & =\text { Poly(oxymethylene) hemiformal } \\ \text { LLE } & =\text { Liquid-liquid equilibrium } \\ \text { MeOH } & =\text { Methanol } \\ \text { MG } & =\text { Poly(oxymethylene) glycol } \\ \text { OME } & =\text { Poly(oxymethylene) dimethyl ether } \\ \text { UNIFAC } & \text { Universal Quasichemical Functional Group Activity } \\ & \text { Coefficients } \\ \text { VLE } & =\text { Vapor-liquid equilibrium }\end{array}$

Symbols and indices

$\begin{array}{ll}a_{i} & =\text { Activity of component } i \\ \gamma_{i} & =\text { Acitivity coefficient of component } i \\ K_{a} & =\text { Activity-based chemical equilibrium constant } \\ n & =\text { Oligomer chain length } \\ p & =\text { Pressure } \\ Q & =\text { UNIFAC surface parameter } \\ R & =\text { UNIFAC size parameter } \\ T & =\text { Temperature } \\ \tau & =\text { Dimensionless time }\end{array}$


$x_{i} \quad=$ True mole fraction of component $i$ in the liquid phase

$x_{i}^{(m)} \quad=$ Mass fraction of component $i$ in the liquid phase

$\tilde{x}_{i}^{(m)} \quad=$ Overall mass fraction of component $i$ in the liquid phase

$y_{i}^{(m)} \quad=$ Mass fraction of component $i$ in the vapor phase

$\tilde{y}_{i}^{(m)} \quad=$ Overall mass fraction of component $i$ in the vapor phase

\section{Acknowledgement}

This work was funded by the German Federal Ministry of Food and Agriculture (BMEL) through grant 22403914. 


\section{References}

[1] B. Lumpp, D. Rothe, C. Pastötter, R. Lämmermann, E. Jacob, Oxymethylene ethers as diesel fuel additives of the future, MTZ 72 (3) (2011) 34-38. doi:10.1365/s38313-011-0027-z.

[2] M. Härtl, P. Seidenspinner, E. Jacob, G. Wachtmeister, Oxygenate screening on a heavy-duty diesel engine and emission characteristics of highly oxygenated oxymethylene ether fuel, Fuel 153 (2015) 328-335. doi:10.1016/j.fuel.2015.03.012.

[3] J. Burger, M. Siegert, E. Ströfer, H. Hasse, Poly(oxymethylene) dimethyl ethers as components of tailored diesel fuel: Properties, synthesis and purification concepts, Fuel 89 (11) (2010) 3315-3319. doi:10.1016/j.fuel.2010.05.014.

[4] J. Burger, A novel process for the production of diesel fuel additives by hierarchical design, Ph.D. thesis, TU Kaiserslautern, Kaiserslautern (2012).

[5] S. Baranton, H. Uchida, D. A. Tryk, J. L. Dubois, M. Watanabe, Hydrolyzed polyoxymethylenedimethylethers as liquid fuels for direct oxidation fuel cells, Electrochim. Acta 108 (2013) 350-355. doi:10.1016/j.electacta.2013.06.138.

[6] D. Devaux, H. Yano, H. Uchida, J.-L. Dubois, M. Watanabe, Electrooxidation of hydrolysed poly-oxymethylene-dimethylether on $\mathrm{PtRu}$ supported catalysts, Electrochim. Acta 56 (3) (2011) 1460-1465. doi:10.1016/j.electacta.2010.10.088. 
[7] Q. Liu, X. Zhang, B. Ma, Solubility of 2-ethylanthraquinone in binary mixtures of oligooxymethylene dimethyl ethers with different number of $\mathrm{CH}_{2} \mathrm{O}$ groups of $n=2,3$, and 4 from 293.15 to $343.15 \mathrm{~K}$, J. Chem. Eng. Data 61 (9) (2016) 3254-3265. doi:10.1021/acs . jced.6b00334.

[8] J. Burger, V. Papaioannou, S. Gopinath, G. Jackson, A. Galindo, C. S. Adjiman, A hierarchical method to integrated solvent and process design of physical $\mathrm{CO}_{2}$ absorption using the SAFT- $\gamma$ mie approach, AIChE J. 61 (10) (2015) 3249-3269. doi:10.1002/aic.14838.

[9] M. Schappals, T. Breug-Nissen, K. Langenbach, J. Burger, H. Hasse, Solubility of carbon dioxide in poly(oxymethylene) dimethyl ethers, J. Chem. Eng. Data 62 (11) (2017) 4027-4031. doi:10.1021/acs.jced.7b00718.

[10] J. Zhang, D. Fang, D. Liu, Evaluation of zr-alumina in production of polyoxymethylene dimethyl ethers from methanol and formaldehyde: Performance tests and kinetic investigations, Ind. Eng. Chem. Res. 53 (35) (2014) 13589-13597. doi:10.1021/ie501231a.

[11] J. Zhang, M. Shi, D. Fang, D. Liu, Reaction kinetics of the production of polyoxymethylene dimethyl ethers from methanol and formaldehyde with acid cation exchange resin catalyst, React. Kinet. Mech. Cat. 11 (2) (2014) 459-470. doi:10.1007/s11144-014-0771-6.

[12] D. Oestreich, L. Lautenschütz, U. Arnold, J. Sauer, Reaction kinetics and equilibrium parameters for the production of oxymethylene 
dimethyl ethers (ome) from methanol and formaldehyde, Chem. Eng. Sci. 163 (2017) 92-104. doi:10.1016/j.ces.2016.12.037.

[13] D. Oestreich, L. Lautenschütz, U. Arnold, J. Sauer, Production of oxymethylene dimethyl ether (OME)-hydrocarbon fuel blends in a one-step synthesis/extraction procedure, Fuel 214 (2018) 39-44. doi:10.1016/j.fuel.2017.10.116.

[14] N. Schmitz, F. Homberg, J. Berje, J. Burger, H. Hasse, Chemical equilibrium of the synthesis of poly(oxymethylene) dimethyl ethers from formaldehyde and methanol in aqueous solutions, Ind. Eng. Chem. Res. 54 (25) (2015) 6409-6417. doi:10.1021/acs.iecr.5b01148.

[15] N. Schmitz, J. Burger, H. Hasse, Reaction kinetics of the formation of poly(oxymethylene) dimethyl ethers from formaldehyde and methanol in aqueous solutions, Ind. Eng. Chem. Res. 54 (50) (2015) 12553-12560. doi:10.1021/acs.iecr.5b04046.

[16] I. Hahnenstein, H. Hasse, C. G. Kreiter, G. Maurer, 1H- and 13C-NMRspectroscopic study of chemical equilibria in solutions of formaldehyde in water, deuterium oxide, and methanol, Ind. Eng. Chem. Res. 33 (4) (1994) 1022-1029. doi:10.1021/ie00028a033.

[17] I. Hahnenstein, M. Albert, H. Hasse, C. G. Kreiter, G. Maurer, NMR spectroscopic and densimetric study of reaction kinetics of formaldehyde polymer formation in water, deuterium oxide, and methanol, Ind. Eng. Chem. Res. 34 (2) (1995) 440-450. doi:10.1021/ie00041a003. 
[18] M. Albert, Thermodynamische eigenschaften formaldehydhaltiger mischungen, Ph.D. Thesis, TU Kaiserslautern, Kaiserslautern (1998).

[19] C. Kuhnert, M. Albert, S. Breyer, I. Hahnenstein, H. Hasse, G. Maurer, Phase equilibrium in formaldehyde containing multicomponent mixtures: Experimental results for fluid phase equilibria of (formaldehyde + (water or methanol $)+$ methylal $))$ and (formaldehyde + water + methanol + methylal) and comparison with predictions, Ind. Eng. Chem. Res. 45 (14) (2006) 5155-5164. doi:10.1021/ie060131u.

[20] G. Maurer, Vapor-liquid equilibrium of formaldehyde-and watercontaining multicomponent mixtures, AIChE J. 32 (6) (1986) 932-948. doi:10.1002/aic.690320604.

[21] Y. Song, Q. Li, D. Jianfei, Z. Haipeng, L. Xuefeng, S. Xiang, Vaporliquid equilibrium for methanol-methylal-poly methoxy methylal $(\mathrm{n}=2)$ system, Chemical Engineering (China) 43 (2).

[22] J. Burger, E. Ströfer, H. Hasse, Production process for diesel fuel components poly(oxymethylene) dimethyl ethers from methane-based products by hierarchical optimization with varying model depth, Chem. Eng. Res. Des. 91 (12) (2013) 2648-2662. doi:10.1016/j.cherd.2013.05.023.

[23] N. Schmitz, E. Ströfer, J. Burger, H. Hasse, Conceptual design of a novel process for the production of poly(oxymethylene) dimethyl ethers from formaldehyde and methanol, Ind. Eng. Chem. Res. 56 (40) (2017) 11519-11530. doi:10.1021/acs.iecr.7b02314. 
[24] H. Hasse, I. Hahnenstein, G. Maurer, Revised vapor-liquid equilibrium model for multicomponent formaldehyde mixtures, AIChE J. 36 (12) (1990) 1807-1814. doi:10.1002/aic.690361204.

[25] H. Hasse, G. Maurer, Vapor-liquid equilibrium of formaldehydecontaining mixtures at temperatures below $320 \mathrm{~K}$, Fluid Phase Equilib. 64 (1991) 185-199. doi:10.1016/0378-3812(91) 90013-W.

[26] M. Albert, I. Hahnenstein, H. Hasse, G. Maurer, Vapor-liquid equilibrium of formaldehyde mixtures: New data and model revision, AIChE J. 42 (6) (1996) 1741-1752. doi:10.1002/aic.690420625.

[27] M. Albert, B. Coto Garcia, C. Kreiter, G. Maurer, Vapor-liquid and chemical equilibria of formaldehyde-water mixtures, AIChE J. 45 (9) (1999) 2024-2033. doi:10.1002/aic.690450919.

[28] M. Albert, B. Coto Garcia, C. Kuhnert, R. Peschla, G. Maurer, Vaporliquid equilibrium of aqueous solutions of formaldehyde and methanol, AIChE J. 46 (8) (2000) 1676-1687. doi:10.1002/aic.690460818.

[29] M. Albert, I. Hahnenstein, H. Hasse, G. Maurer, Vapor-liquid and liquid-liquid equilibria in binary and ternary mixtures of water, methanol, and methylal, J. Chem. Eng. Data 46 (4) (2001) 897-903. doi:10.1021/je0003521.

[30] M. Maiwald, H. H. Fischer, M. Ott, R. Peschla, C. Kuhnert, C. G. Kreiter, G. Maurer, H. Hasse, Quantitative NMR spectroscopy of complex liquid mixtures: methods and results for chemical equilibria in 
formaldehyde-water-methanol at temperatures up to $383 \mathrm{~K}$, Ind. Eng. Chem. Res. 42 (2) (2003) 259-266. doi:10.1021/ie0203072.

[31] M. Albert, H. Hasse, C. Kuhnert, G. Maurer, New experimental results for the vapor-liquid equilibrium of the binary system (trioxane + water) and the ternary system (formaldehyde + trioxane + water), J. Chem. Eng. Data 50 (4) (2005) 1218-1223. doi:10.1021/je050015i.

[32] N. Schmitz, A. Friebel, E. von Harbou, J. Burger, H. Hasse, Liquid-liquid equilibrium in binary and ternary mixtures containing formaldehyde, water, methanol, methylal, and poly(oxymethylene) dimethyl ethers, Fluid Phase Equilib. 425 (2016) 127-135. doi:10.1016/j.fluid.2016.05.017.

[33] M. Ott, H. Schoenmakers, H. Hasse, Distillation of formaldehyde containing mixtures: laboratory experiments, equilibrium stage modeling and simulation, Chem. Eng. Process 44 (6) (2005) 687-694. doi:10.1016/j.cep.2003.09.011.

[34] J.-O. Weidert, J. Burger, M. Renner, S. Blagov, H. Hasse, Development of an integrated reaction-distillation process for the production of methylal, Ind. Eng. Chem. Res. 56 (2) (2017) 575-582. doi:10.1021/acs.iecr.6b03847.

[35] Rayleigh, Lix. on the distillation of binary mixtures, Phil Mag S 4 (23) (1902) 521-537. doi:10.1080/14786440209462876.

[36] H. Hasse, Dampf-Flüssigkeits-Gleichgewichte, Enthalpien und Reaktion- 
skinetik in formaldehydhaltigen Mischungen, Ph.D. thesis, TU Kaiserslautern, Kaiserslautern (1990).

[37] J.-O. Drunsel, Entwicklung von Verfahren zur Herstellung von Methylal und Ethylal, Ph.D. Thesis, TU Kaiserslautern, Kaiserslautern (2012).

[38] J.-O. Drunsel, M. Renner, H. Hasse, Experimental study and model of reaction kinetics of heterogeneously catalyzed methylal synthesis, Chem. Eng. Res. Des. 90 (5) (2012) 696-703. doi:10.1016/j.cherd.2011.09.014. 
Table 1: Parameters for the calculation of the activity-based chemical equilibrium constants $K_{a}(T)$ for the formation of poly(oxymethylene) glycols and poly(oxymethylene) hemiformals, reactions (1) to (4), using the correlation: $\ln K_{a}(T)=A+B /(T / \mathrm{K})+C$. $\ln (T / \mathrm{K})+\underline{D \cdot(T / \mathrm{K})[19,38]}$

\begin{tabular}{lcccc}
\hline Reaction & $A$ & $B$ & $C$ & $D$ \\
\hline$(1)$ & -30.946 & 4819.0 & 3.7410 & $-4.5340 \cdot 10^{-3}$ \\
$(2)(n=2)$ & -30.941 & 5653.0 & 3.7410 & $-4.5340 \cdot 10^{-3}$ \\
$(2)(n \geq 3)$ & -30.933 & 5361.0 & 3.7410 & $-4.5340 \cdot 10^{-3}$ \\
$(3)$ & 1129.7 & -25100 & -198.40 & 0.3160 \\
$(4)(n=2)$ & 1129.0 & -25510 & -198.40 & 0.3160 \\
$(4)(n \geq 3)$ & 1129.0 & -25630 & -198.40 & 0.3160 \\
\hline
\end{tabular}


Table 2: UNIFAC structural groups with size and surface parameters. The parameters were adopted from Albert [18] and Schmitz et al. [32]

\begin{tabular}{lccc}
\hline Structural group & Number & $R$ & $Q$ \\
\hline $\mathrm{CH}_{2} \mathrm{O}$ & 1 & 0.9183 & 0.780 \\
$\mathrm{H}_{2} \mathrm{O}$ & 2 & 0.9200 & 1.400 \\
$\mathrm{H}_{3} \mathrm{C}-\mathrm{O}-\mathrm{CH}_{2} \mathrm{O}-\mathrm{CH}_{3}$ & 3 & 2.9644 & 2.716 \\
$\mathrm{HO}-\mathrm{CH}_{2} \mathrm{O}-\mathrm{H}$ & 4 & 2.6744 & 2.940 \\
$\mathrm{OH}$ & 5 & 1.0000 & 1.200 \\
$\mathrm{CH}_{2}$ & 6 & 0.6744 & 0.540 \\
$\mathrm{CH}_{3} \mathrm{O}$ & 7 & 1.1459 & 1.088 \\
$\mathrm{CH}_{2} \mathrm{OH}$ & 8 & 1.2044 & 1.124 \\
$\mathrm{CH}_{3} \mathrm{OH}$ & 9 & 1.4311 & 1.432 \\
$\left(\mathrm{CH}_{2} \mathrm{O}\right)_{\text {OME }}$ & 10 & 0.9183 & 0.780 \\
$\left(\mathrm{CH}_{2} \mathrm{O}\right)_{3}$ & 11 & 2.7540 & 3.300 \\
\hline & & &
\end{tabular}




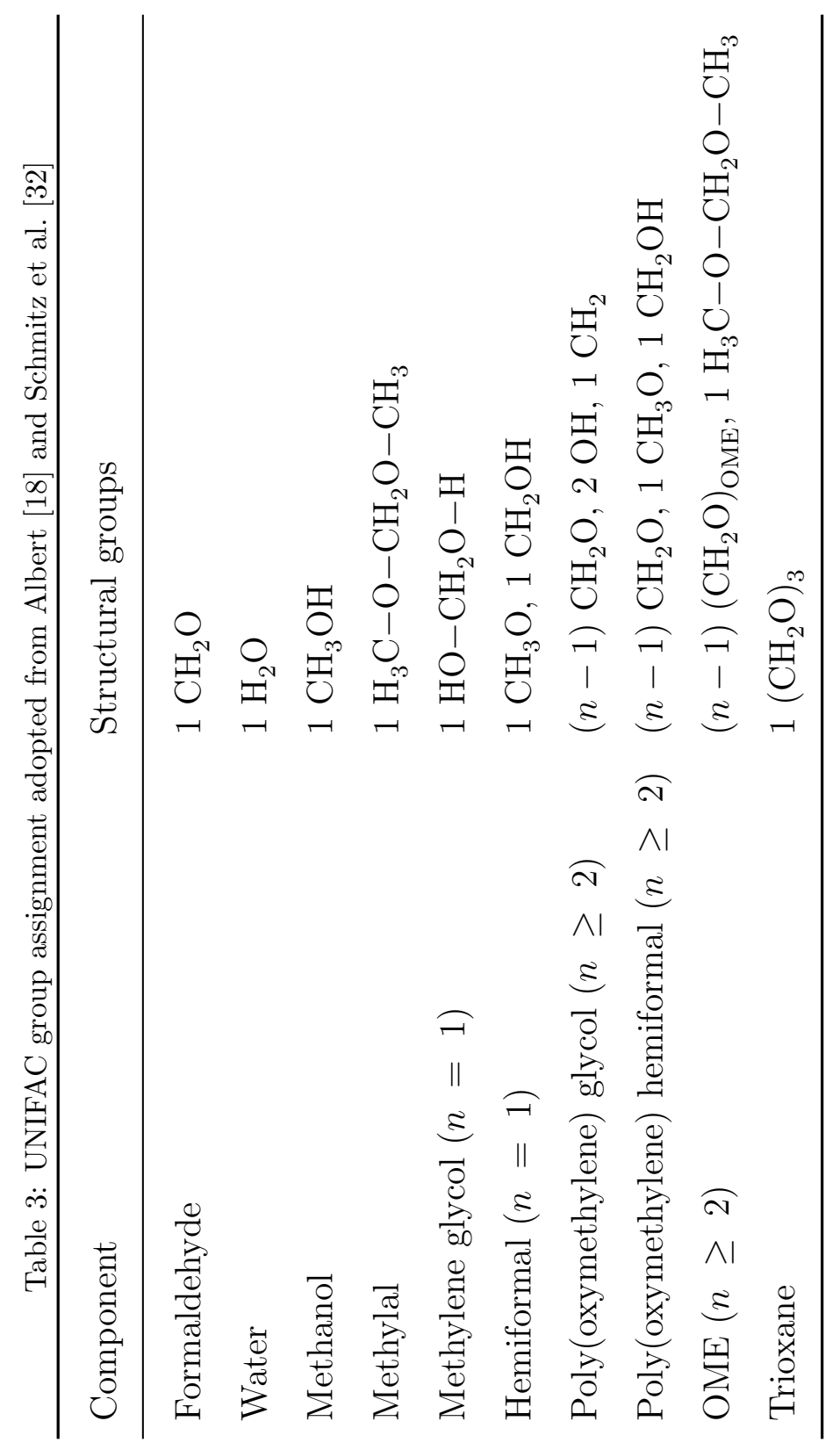




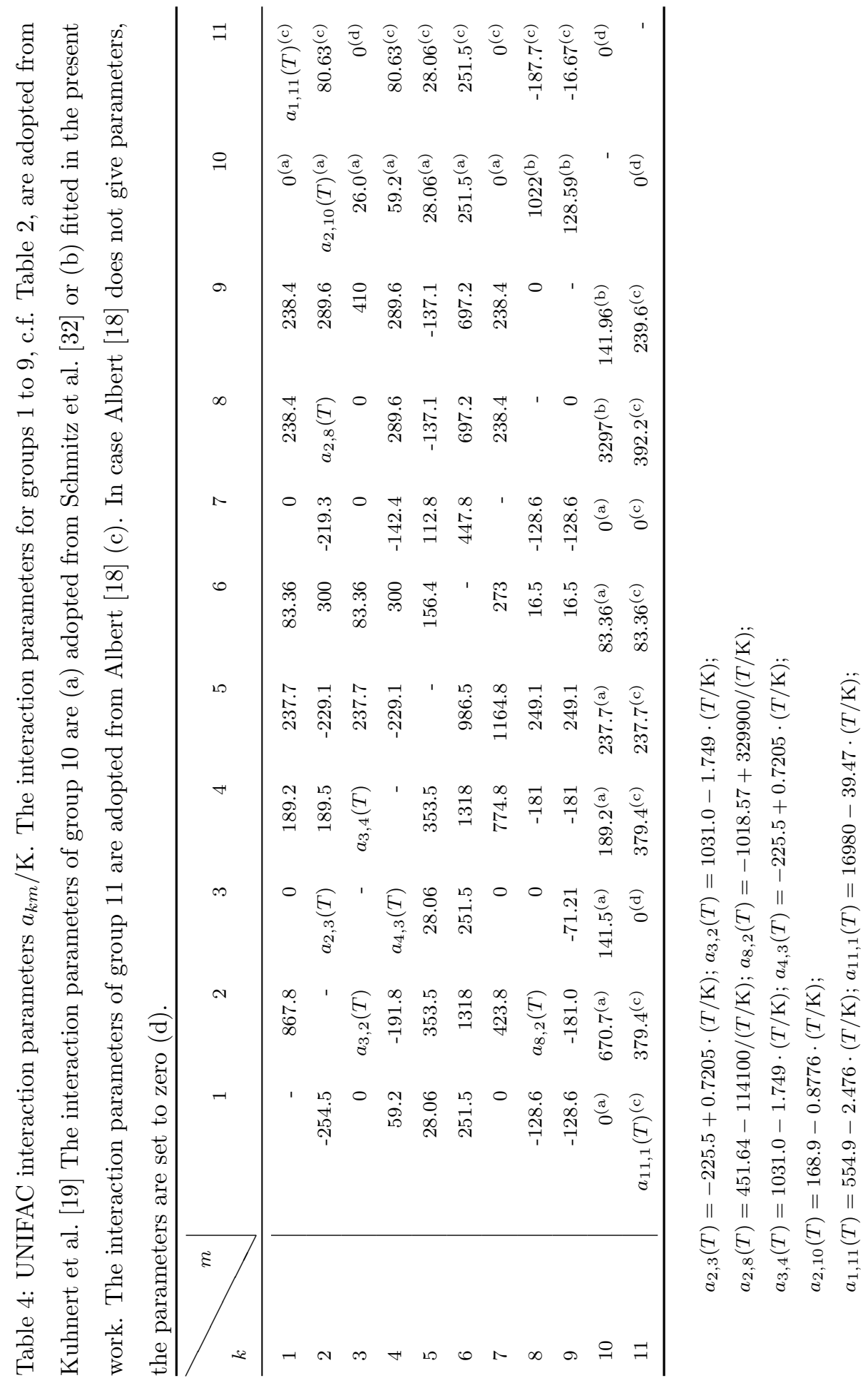




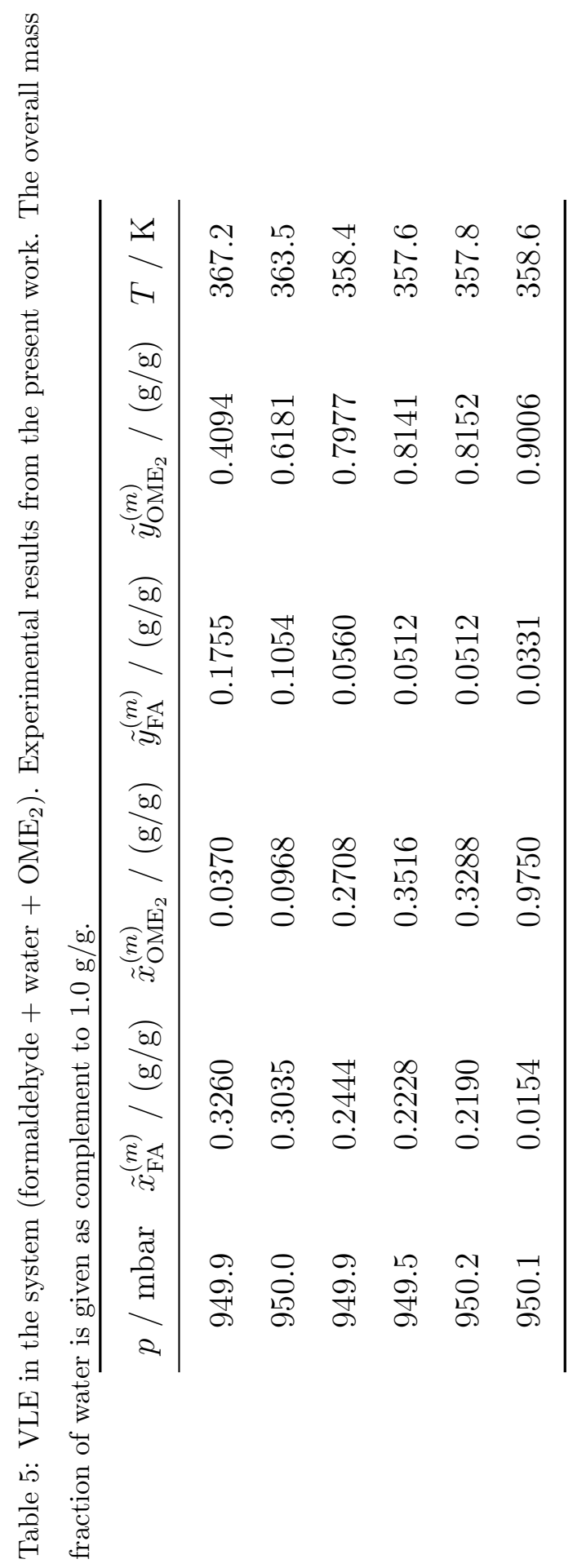




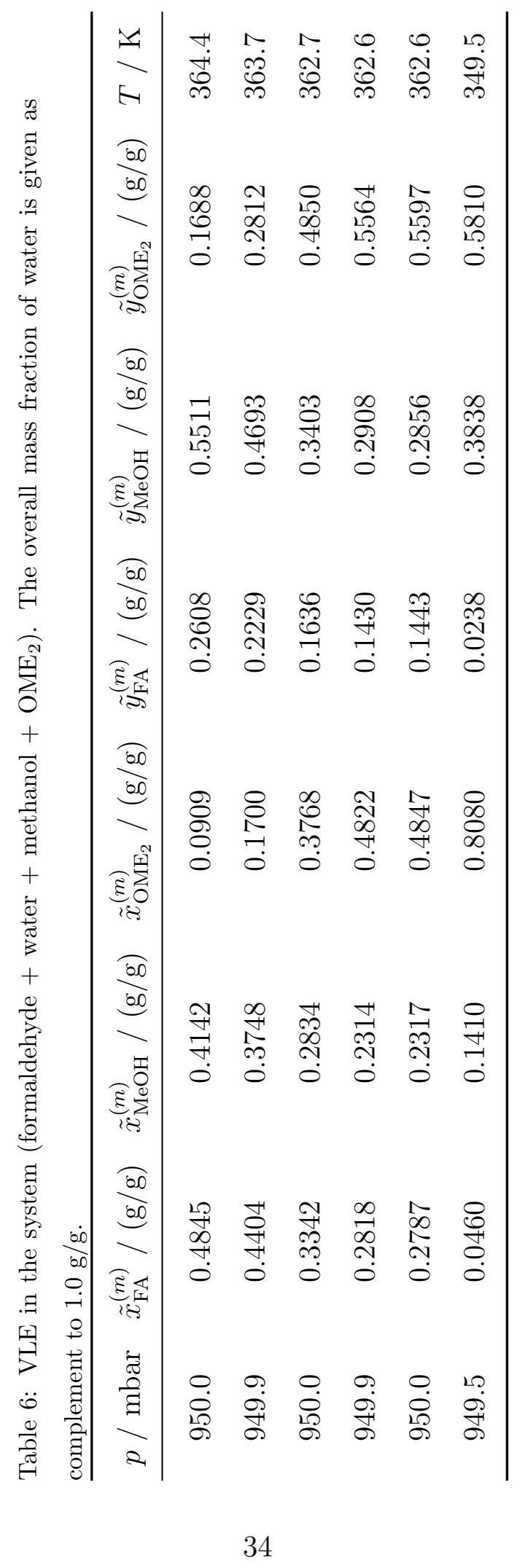


Table 7: Stream table of distillation experiment D1. Experimental values: Top pressure: 979 mbar. Column pressure drop: 9 mbar. Reflux ratio: $2.85 \mathrm{~g} / \mathrm{g}$. Reboiler heat duty: $846 \mathrm{~W}$.

\begin{tabular}{l|ccc}
\hline & Feed & Distillate & Bottom \\
\hline Mass flow $/(\mathrm{g} / \mathrm{min})$ & 25.0 & 12.9 & 11.8 \\
Temperature $/{ }^{\circ} \mathrm{C}$ & 46.3 & 59.2 & 83.2 \\
\hline
\end{tabular}

\begin{tabular}{l|lll}
\multicolumn{4}{c}{ Overall mass fraction $/(\mathrm{g} / \mathrm{g})$} \\
Water & 0.022 & 0.000 & 0.046 \\
Methanol & 0.338 & 0.658 & 0.030 \\
Methylal & 0.172 & 0.341 & 0.000 \\
OME $_{2}$ & 0.445 & 0.000 & 0.877 \\
Trioxane & 0.023 & 0.000 & 0.047
\end{tabular}


Table 8: Stream table of distillation experiment D2. Experimental values: Top pressure: 977 mbar. Column pressure drop: 9 mbar. Reflux ratio: $1.05 \mathrm{~g} / \mathrm{g}$. Reboiler heat duty: $892 \mathrm{~W}$.

\begin{tabular}{l|ccc}
\hline & Feed & Distillate & Bottom \\
\hline Mass flow / (g/min) & 25.0 & 16.8 & 6.9 \\
Temperature $/{ }^{\circ} \mathrm{C}$ & 68.0 & 77.1 & 153.7 \\
\hline
\end{tabular}

\begin{tabular}{l|lll}
\hline \multicolumn{4}{c}{ Overall mass fraction $/(\mathrm{g} / \mathrm{g})$} \\
\hline Formaldehyde & 0.040 & 0.056 & 0.002 \\
Water & 0.048 & 0.069 & 0.000 \\
Methanol & 0.261 & 0.372 & 0.000 \\
Methylal & 0.004 & 0.005 & 0.000 \\
$\mathrm{OME}_{2}$ & 0.284 & 0.402 & 0.000 \\
$\mathrm{OME}_{3}$ & 0.296 & 0.000 & 0.998 \\
Trioxane & 0.067 & 0.096 & 0.000 \\
\hline
\end{tabular}




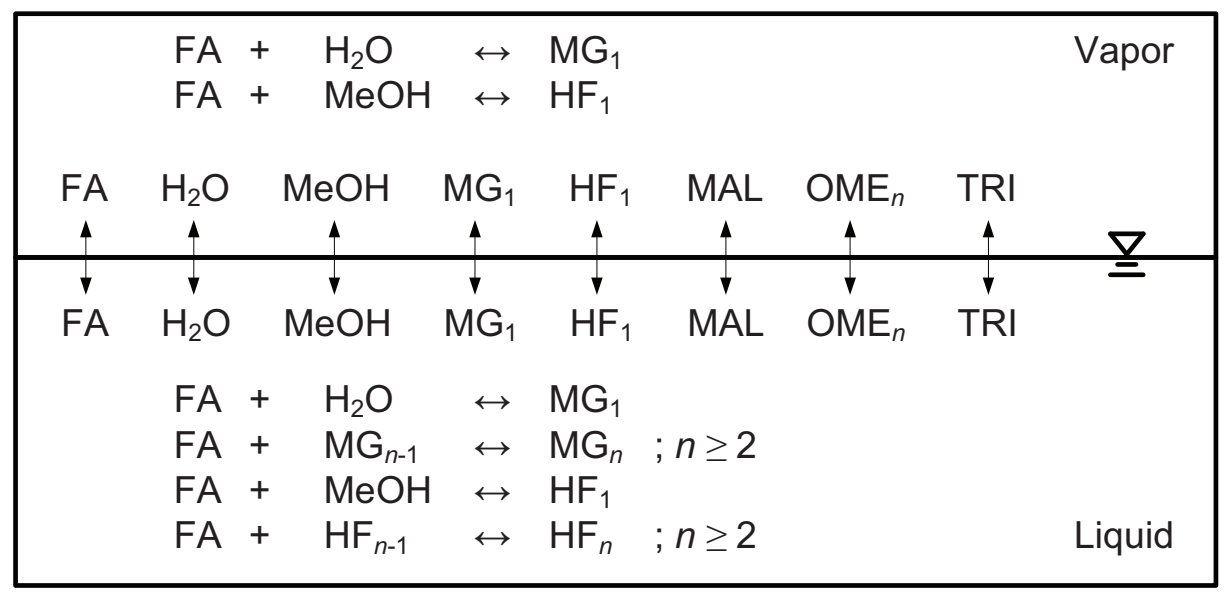

Figure 1: Scheme of the VLE model in the system (formaldehyde + water + methanol + methylal + OME + trioxane).

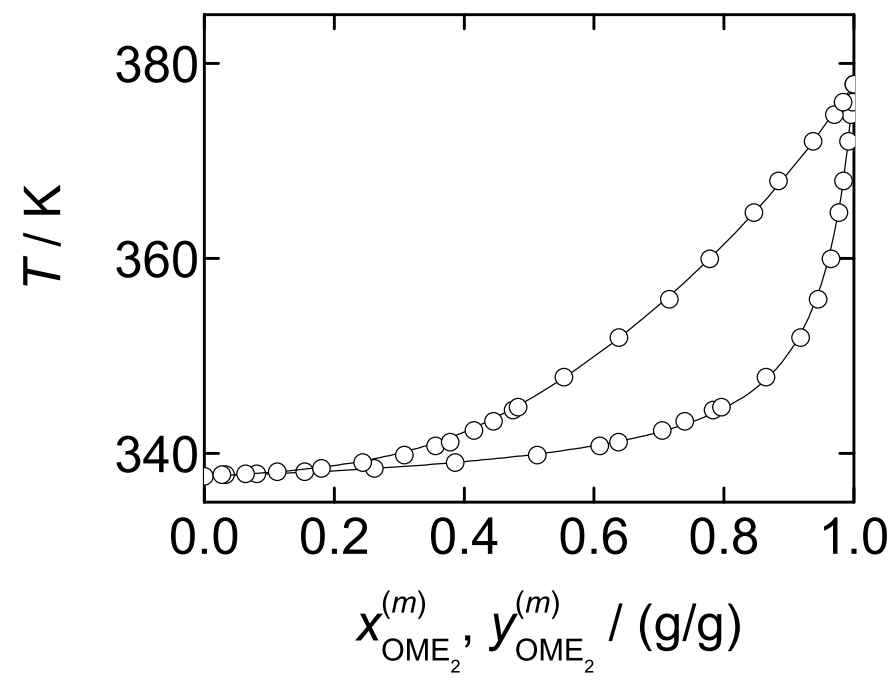

Figure 2: VLE in the system (methanol $+\mathrm{OME}_{2}$ ) at 1.013 bar. (o) Experimental results from Song et al. [21]. Lines: Model (this work). 


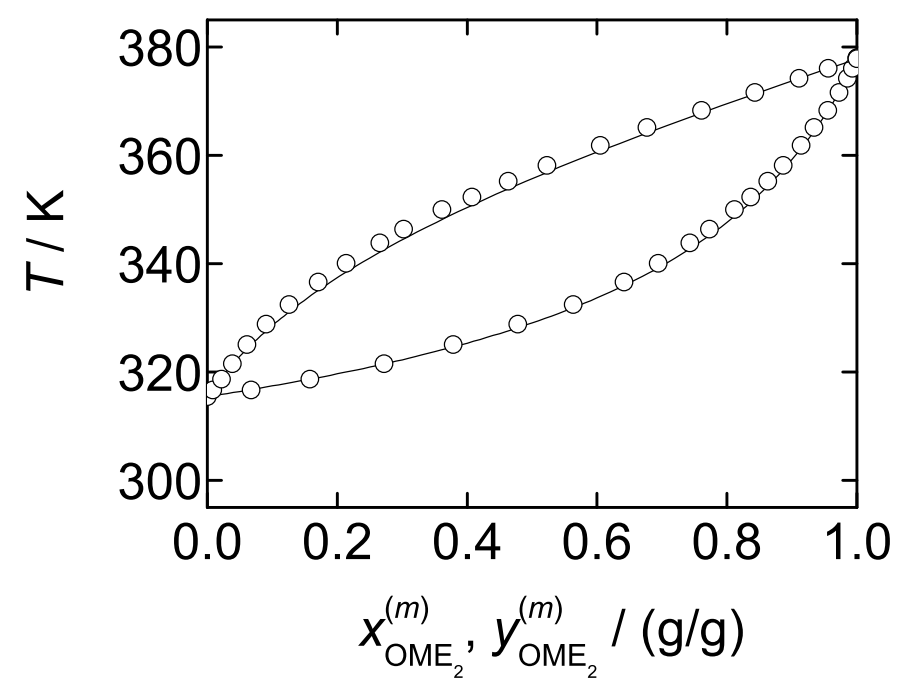

Figure 3: VLE in the system (methylal $+\mathrm{OME}_{2}$ ) at 1.013 bar. (०) Experimental results from Song et al. [21]. Lines: Model (this work). 

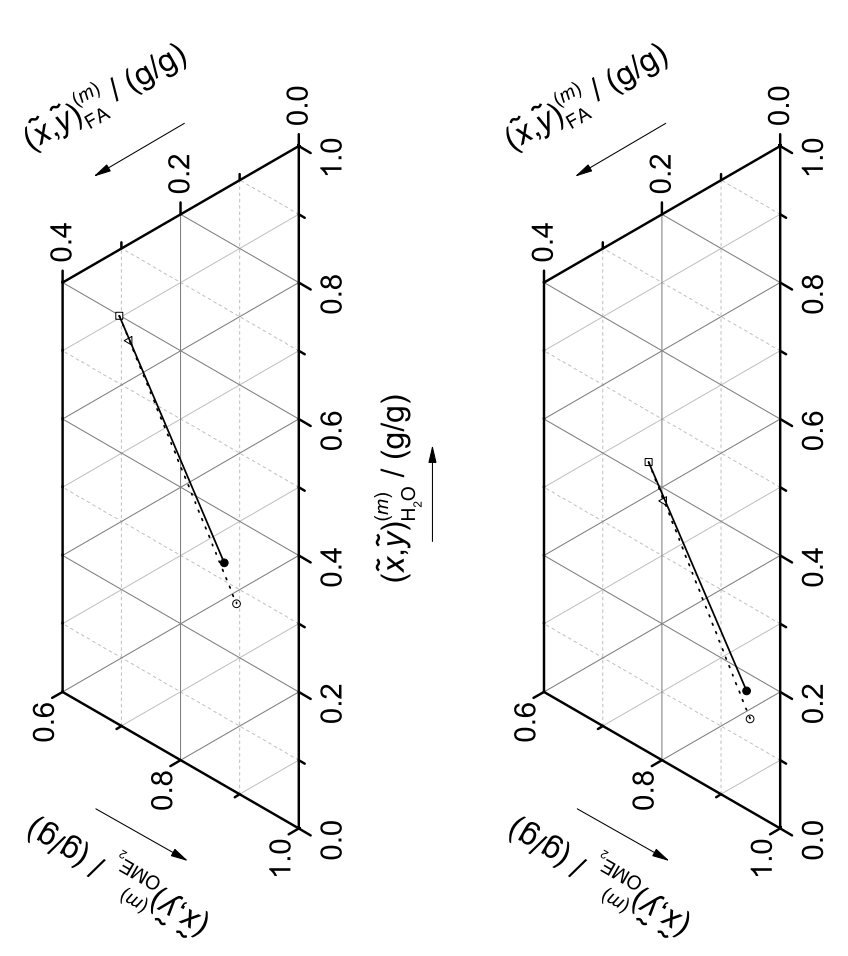

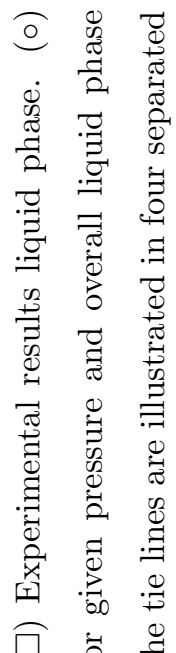
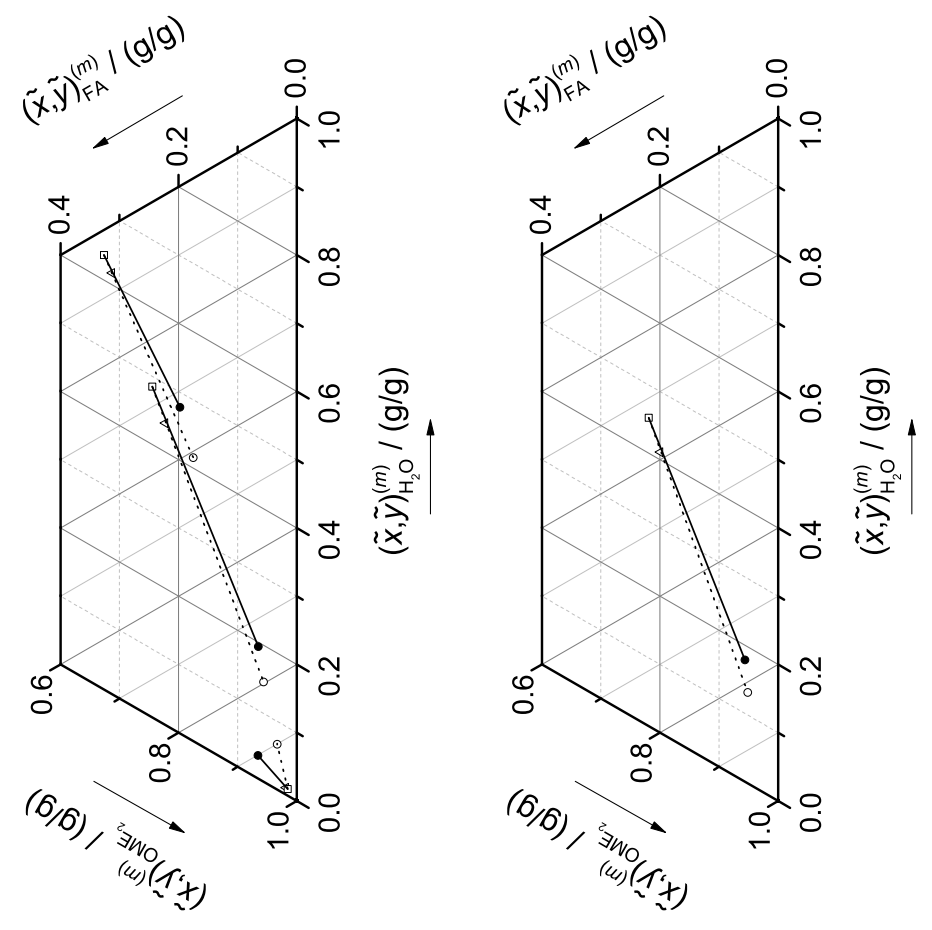

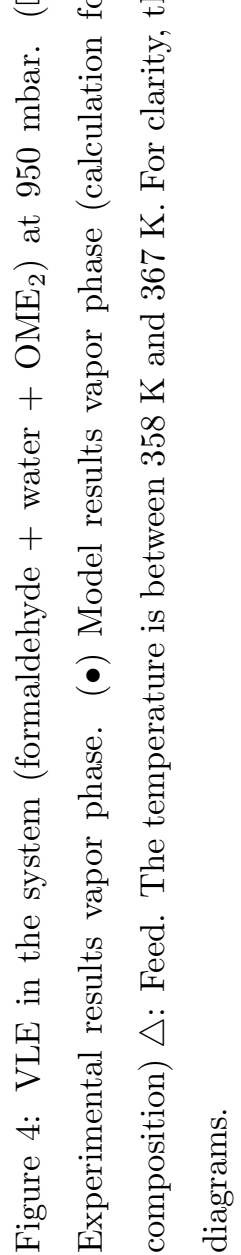




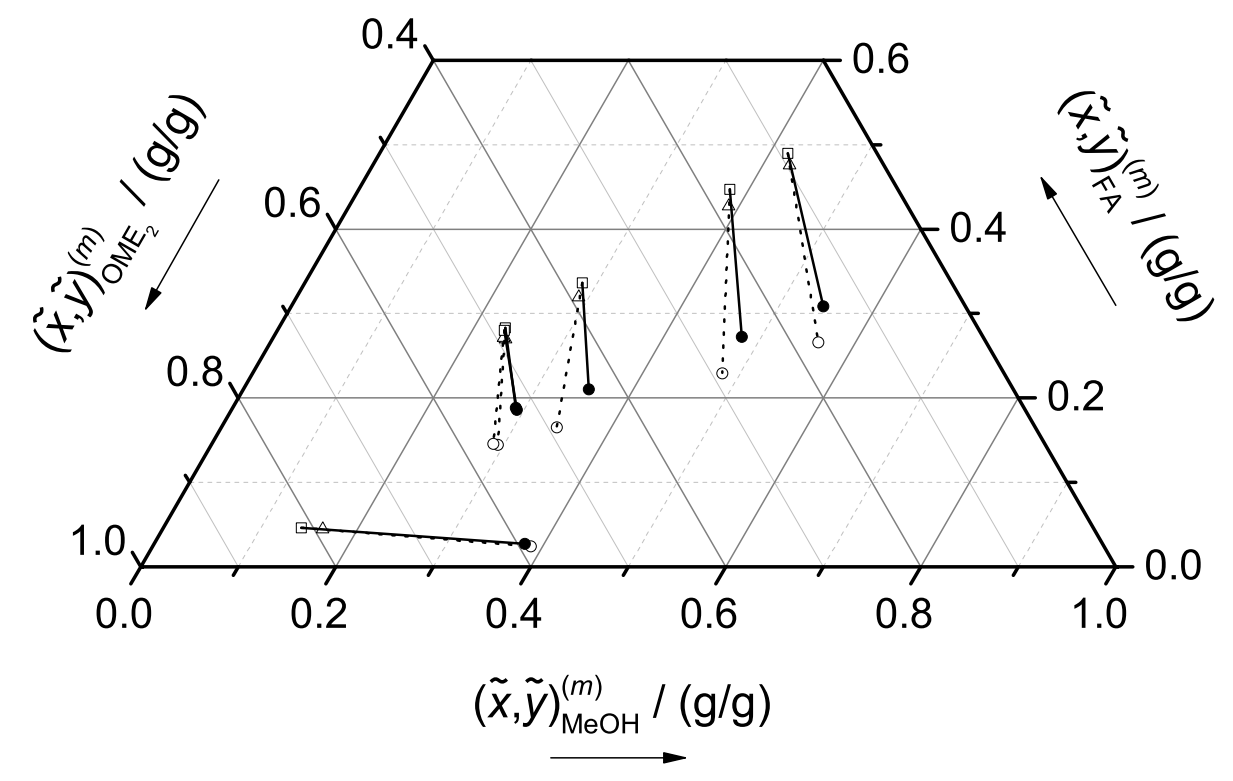

Figure 5: VLE in the system (formaldehyde + water + methanol $+\mathrm{OME}_{2}$ ) at 950 mbar. The overall mass fraction of water is smaller than $0.027 \mathrm{~g} / \mathrm{g}$ in all cases. For clarity of the graphical illustration, the concentrations are projected into the ternary system (formaldehyde + methanol $+\mathrm{OME}_{2}$ ) by proportional weighting. Water was considered in the analysis and the model calculation. ( $\square$ ) Experimental results liquid phase. (०) Experimental results vapor phase. $(\bullet)$ Model results vapor phase (calculation for given pressure and overall liquid phase composition) $\triangle$ : Feed. The measured temperature is between $350 \mathrm{~K}$ and $364 \mathrm{~K}$. 


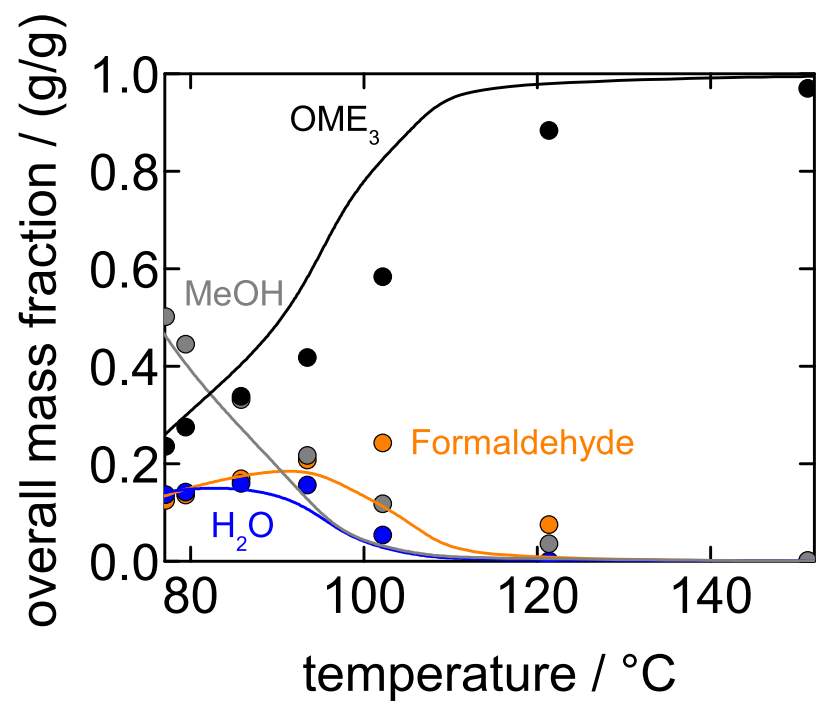

Figure 6: Overall composition and temperature of the liquid residue for batch evaporation experiment B1 at 980 mbar. Symbols: Experimental results. Lines: Model calculation of the residue curve by numerical integration of Eq. (9). It is assumed that the VLE between the liquid residue and the emerging vapor is always established. The vapor phase composition $\tilde{y}_{i}^{(m)}$ and the temperature $T\left(p, \tilde{x}_{i}^{(m)}\right)$ are calculated using the model of this work. 


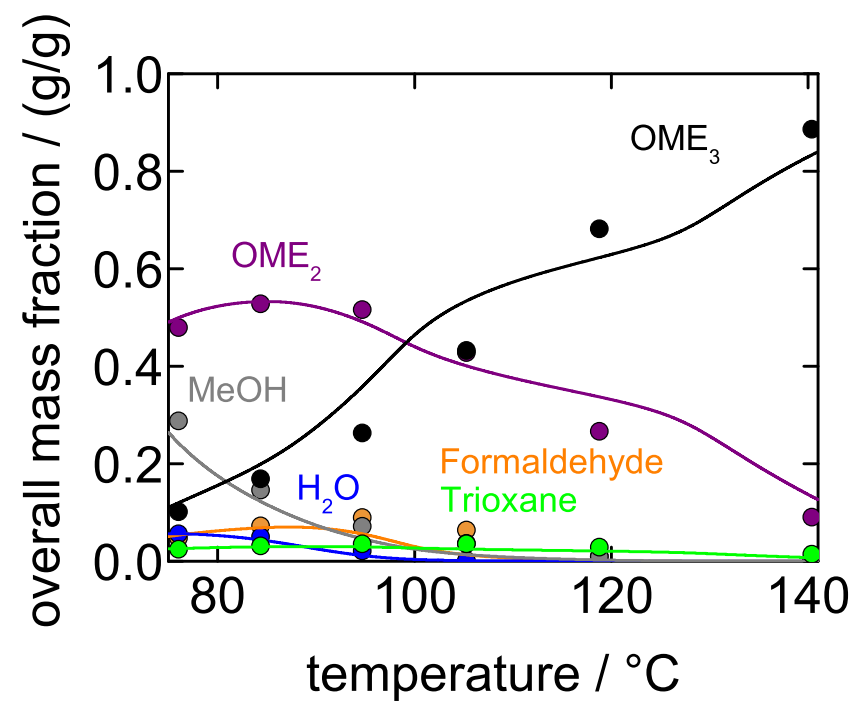

Figure 7: Overall composition and temperature of the liquid residue for batch evaporation experiment B2 at 980 mbar. Symbols: Experimental results. Lines: Model calculation of the residue curve by numerical integration of Eq. (9). It is assumed that the VLE between the liquid residue and the emerging vapor is always established. The vapor phase composition $\tilde{y}_{i}^{(m)}$ and the temperature $T\left(p, \tilde{x}_{i}^{(m)}\right)$ are calculated using the model of this work. 

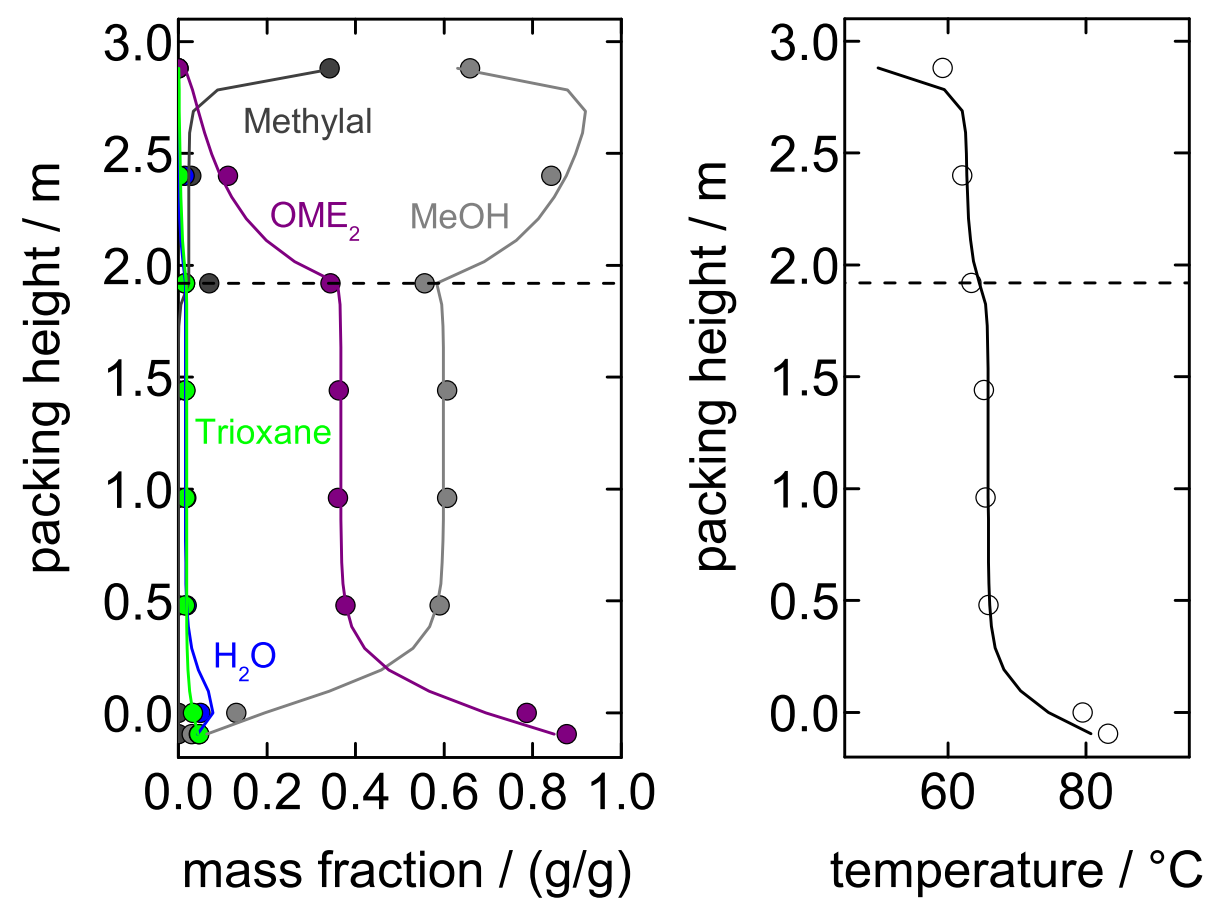

Figure 8: Profiles of mass fractions in the liquid phase and temperature of distillation experiment D1 at a top pressure of 979 mbar. Symbols: Experimental results. Lines: Simulation using equilibrium stage model, where the mass fraction of $\mathrm{OME}_{2}$ at $0.48 \mathrm{~m}$ and reflux ratio were specified. Dashed line: Feed position. 

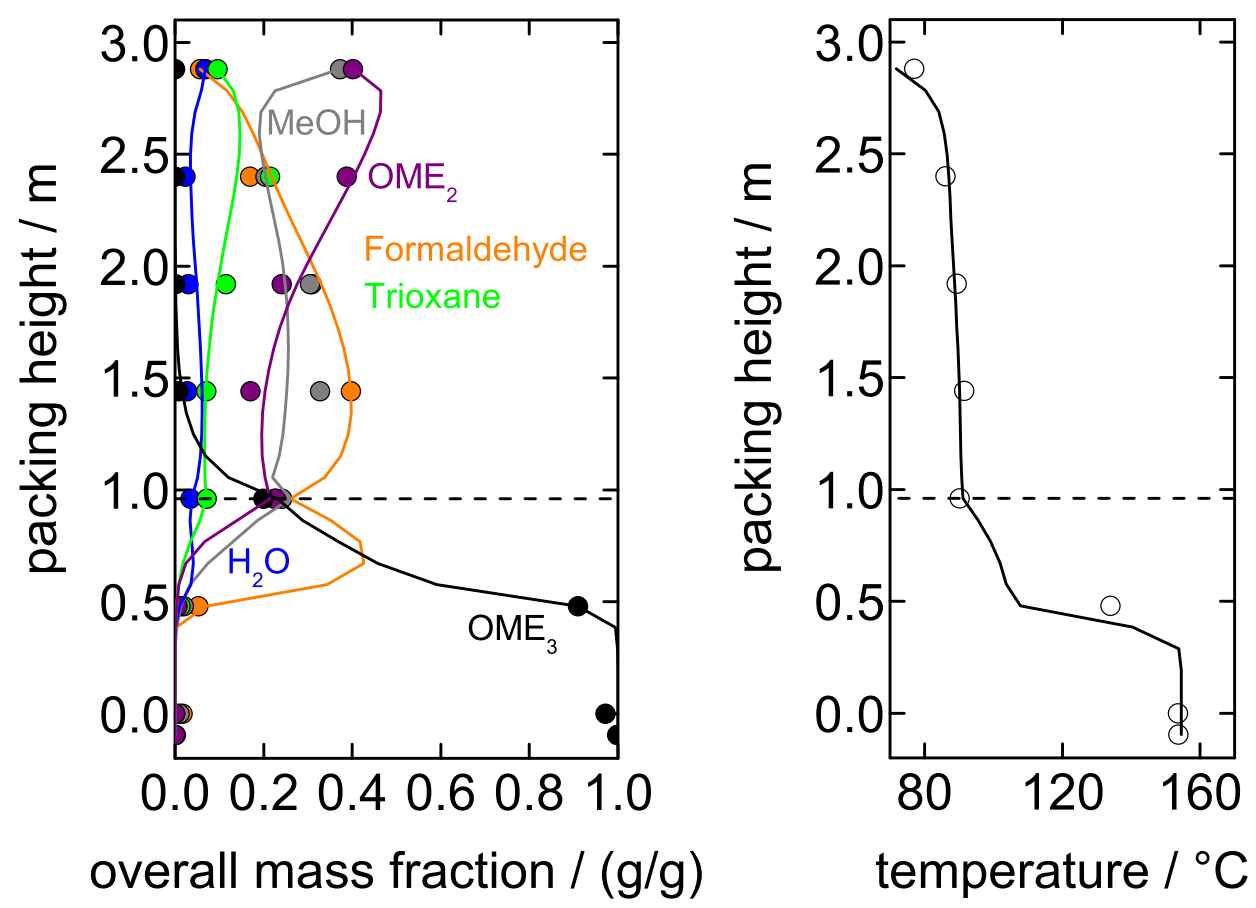

Figure 9: Profiles of overall mass fractions in the liquid phase and temperature of distillation experiment D2 at a top pressure of 977 mbar. Symbols: Experimental results. Lines: Simulation using equilibrium stage model, where the overall mass fraction of $\mathrm{OME}_{3}$ at $0.48 \mathrm{~m}$ and the overall mass fraction of formaldehyde at $1.44 \mathrm{~m}$ packing height were specified. Dashed line: Feed position. 